\title{
Irony as a characteristic feature of journalists' speech behaviour
}

\author{
Gyulnara Basenko $^{1}$, Victoria Baskakova $^{1}$, and Elena Sakharova ${ }^{1 *}$ \\ ${ }^{1}$ Don State Technical University, pl. Gagarina, 1, Rostov-on-Don, Russia
}

\begin{abstract}
This article deals with studying the characteristic features of ironic statements functioning in the speech behaviour of German journalists. The article identifies the strategic aspects of ironic statements in the communicative space of the German-language media discourse. The article reveals the phenomenon of irony from the point of view of the pragmalinguistic approach. The authors analyze the speech behaviour of German journalists according to the speech strategy "the formation of an ironic meaning in the statement". The tactics by which this strategy is realized in the newspaper texts are discussed in detail. The study covers various newspaper genres and includes the analysis of examples with irony in the journalists' articles which are particularly characterized by an ironic presentation. Based on the above, it is concluded that irony can be a characteristic feature of journalists' speech behaviour.
\end{abstract}

\section{Introduction}

The study of speech behaviour of message senders in the professional sphere is one of the promising tasks in the modern linguistic science and has repeatedly become the subject of study in various aspects [1-5]. Of particular importance is the study of linguo-cognitive [6, 7] and pragmalinguistic communication mechanisms [5, 8]. The objective of the current article was to investigate, in the aspect of pragmatics, the characteristic features of ironic statements in the speech behaviour of German journalists.

In linguistics there are several approaches to the phenomenon of irony. The first approach considers irony in the narrow sense and lies in the area of stylistics. Stylistics represents irony as one of many tropes. Tropes are lexical pictorial and expressive means in which a word or a phrase is used in a transformed meaning. In the trope system, irony is understood as a stylistic device based on the principle of "using a word in a statement with a semantic shift" [9], in the reverse of the literal sense, that is, based on antiphrasis relations.

The second approach is based on the communicative aspect of language learning and considers irony as a discrepancy in the broadest sense between the expressed and the implied, as a contradiction between the evaluative signs of the explicit and implicit plans of the text. The communicative aspect includes a wide context and an extralinguistic situation in the field of research. Irony obtains a more complex form, where words are used not in

\footnotetext{
* Corresponding author: elenasakharova@bk.ru
} 
their directly opposite meanings, but a great diversity of ironic meanings, taking into account the semantics of words, context, extralinguistic situation and background knowledge of the addressee. Irony is presented in the form of evaluative, critical, emotional perception of reality by the author of an ironic statement; it realizes a subjective hidden evaluative modality with a negative component.

From the point of the cognitive science, irony lies in the deliberate violation of the standard. Moreover, the ironic effect is possible in the absence of signs of irony, expressed at the linguistic level. Irony is realized in this case as a violation of logical connections in the statement. Note that the comic component is not a key characteristic of irony and is not necessarily presented in an ironic statement. On the other hand, evaluativeness is always expressed in an ironic statement, which proves irony to be a modal category.

\section{Materials and methods}

Let us consider the phenomenon of irony from a pragmatic standpoint in detail. In pragmatics, irony in the axiological aspect is determined by the laws of speech communication. Speech communication as a form of human interaction with the use of language, as a rule, is not limited to the information transfer. In a communication situation, the author of the statement, consciously or unconsciously, sets himself the task of influencing the interlocutor, in accordance with which he chooses the style of communication, sentence structures and words. The communication is considered to be effective, if, along with understanding what has been said, the necessary impact on the person to whom the message is addressed is achieved.

As a means of influence, irony is considered more effective than direct negative evaluation. An ironic statement is flexible, intellectual, less aggressive, less straightforward, it expresses a variety of different feelings and emotions. In ironic statements, the author literally gives a positive evaluation of the character, but criticizing he actually implies a negative one. A direct evaluation of the negative character can cause an undesirable perlocutionary effect on the addressee, in our case it is the reader, namely, a rejection of the author's position as unacceptable. The weakening of the categorical statement softens the negative evaluation and brings it closer to the neutral zone, thus reducing its aggressiveness [4]. Evaluation in the form of irony creates a socially favourable atmosphere and increases the etiquette of communication.

Taking into account the multi-aspects approach to the phenomenon of irony, let us define irony as a communicative modal category realized in the speech act of communication. The ironic meaning appears to be the meaning of discourse, which often contains a negative evaluation, decoded by explicating implicit meanings based on the contradiction between the literal and the implied.

Irony, as one of the methods of hidden influence on the addressee, has become widespread in the modern media space. The press, being one of the popular mass media, goes beyond the simple information transfer and performs the task of influencing the recipient of the message. A wide field for investigation is the study of irony as a characteristic feature of journalists' speech behaviour.

In pragmalinguistics, speech behaviour and speech activity are two notions that are differentiated $[1,2]$. The latter is associated with the conscious choice and actions of the linguistic personality. Speech behaviour is interpreted as a habitual, automated human speech experience, which was formed as a result of repeated repetition in typical communication situations. In this regard, two strategies are distinguished in human speech behaviour - hidden speech strategies, which the author actualizes without hesitation in the usual way $[2,3]$, and communication strategies [10, 11], which are planned and controlled by the author in the process of speech and in turn they create the necessary impact on the 
recipient within the text, in our case the reader. In the text, hidden speech strategies are actualized in the form of speech plans, and communication strategies are realized in the form of tactics.

However, we believe that it is not always possible to distinguish between intentional and habitual (automatic) use of certain linguistic units in a person's speech demonstration. In fact, in the process of communication we use not only well-thought-out units and structures correctly built from grammatical and semantic points of view. We also do a lot out of habit in speech communication, without realizing it. Thus, the approach to speech behaviour as an object of study depends on the research position of the author (scientist).

In the current work, the speech behaviour of German journalists is studied in the aspect of pragmalinguistics, which claims that the collective lingual and speech experience is reflected in human speech behaviour [1, 2]. A person learns a language only in a community, a group: first of all, in a family, and then in other groups (at school, university, etc.). It is important to understand that we learn not only certain linguistic units - individual words and their combinations, but also word-combinations and set-expressions, phraseological units, idioms, proverbs and sayings, jokes, etc., the meaning of which is revealed exclusively in speech. In a communicative situation, we also learn the patterns of behaviour, including the speech behaviour. A person unconsciously imitates and uses certain words, phrases, and at the same time accepts the ways of communication adopted in this community.

At the same time, human speech behaviour is a purely individual use of language in speech [2]. At the same time, the properties of the linguistic personality itself are reflected in speech behaviour: character traits, temperament features, cognitive abilities, educational level, on the basis of which a person - intentionally or unconsciously - uses certain vocabulary in speech, as well as grammatical categories and syntactic constructions in order to influence the interlocutor.

The positive effect of the author's influence on the recipient depends on the ability of strategically conducting the communication, choosing or forming communication strategies and realize them by means of tactics, depending on the intentions of the author.

In our research we introduced the concept of the strategy "the formation of an ironic meaning in the statement" which helped to reveal the characteristic features of irony in the journalists' speech behaviour.

To achieve effective communication, if the author of the newspaper article uses the ironic way of presenting the material, such a principle of speech communication as the "principle of politeness" is put forward $[12,13]$. This principle is to:

- express disapproval as little as possible;

- to reduce disagreement between interlocutors;

- to weaken antipathy.

Taking into account these postulates helps to make communication more effective, establish a favorable psychological atmosphere, get rid of communication barriers $[14,15]$.

We analyzed the articles from the German supra-regional newspaper "Frankfurter Allgemeine Zeitung" [16]. The format of this newspaper does not welcome direct criticism of the described events, people or phenomena. Submission of material containing direct criticism is not effective as a means of influence. For these reasons, the author of a newspaper text should refer to strategies that allow him to influence his reader indirectly, in a hidden, unobtrusive form to present his evaluation, making the reader an accomplice [17], since irony is an indirect evaluation softened by a positive form of presenting the information.

Note that the use of irony is not appropriate in all the genres. Thus, the analysis of the material selected for the study showed (see Table 1) that there is practically no irony in news genres and articles on the political topics that are designed to give the information 
objectively. However, irony is often found in the genres of commentary, feuilleton and travel notes, allowing the author to express his own opinion. In these genres journalists successfully realize a strategy of irony in order to reduce disagreement or disapproval of the events or facts presented.

Table 1. The presence of irony in newspaper genres

\begin{tabular}{|l|c|c|c|c|c|}
\hline $\begin{array}{l}\text { Newspaper } \\
\text { genres }\end{array}$ & News & $\begin{array}{l}\text { Political } \\
\text { article }\end{array}$ & Comment & $\begin{array}{l}\text { Travel } \\
\text { notes }\end{array}$ & $\begin{array}{l}\text { Feuille } \\
\text { ton }\end{array}$ \\
\hline $\begin{array}{l}\text { The presence } \\
\text { of ironic } \\
\text { statements }\end{array}$ & - & - & + & + & + \\
\hline
\end{tabular}

In newspaper discourse, there is no direct reaction of the recipient of the text, and at the same time there is no opportunity to adjust the tactics of influence to the recipient, in this regard, the author must think over the tactics in advance that are designed to carry out his strategy.

\section{Results and discussion}

Let us consider the following examples of the strategy "the formation of an ironic meaning in the statement" by the author of the newspaper article:

Example No. 1.

„,... Our Leif, who had been working as a decorator in Oslo for many years, a creator of the largest troll on earth, that was officially recorded in the Guinness Book of Records, an eighteen-meter colossus made of cement and polyester with a giant nose - a cucumber, he is standing as the King with wide legs apart above the landscape in Finnsater a couple of kilometers south of Mefjord, like the Scandinavian King Kong. For a quarter of the century, Leif has been working on his troll - a monster who, meanwhile, has a wife, six children and a large courtyard of magical creatures. Trolls know how to conjure, so Leif's creature with a huge nose - a cucumber opens the gate and lets us enter his cave, Ali-Baba

J. Strobel y Serra. Let there be light! // Frankfurter Allgemeine Zeitung (from German) [16]

The author says that a certain Leif created the largest troll sculpture in the world, got into the Guinness Book of Records. This sculpture was called a world record-breaking man with a cucumber-shaped nose by the author. The author of the article uses the tactics of praise, where the components have a positive meaning in the composition of a compound noun - a world record. Describing this sculpture, he introduces such nouns as: "colossus", "the largest troll on earth", "the Guinness Book of Records". All this vocabulary was used to emphasize the dignity of the sculpture.

But it should be noted that along with the tactics of praise, the tactics of praise refutation were used. The author calls this sculpture the northern King Kong, and this character evokes rather negative associations. King Kong is not the model, which means that the author does not correlate the mentioned sculpture with the standard. The proper name "King Kong" is used with an expressive negative connotation. The dignity of the sculpture is diminished by the fact that the author focuses on the huge cucumber nose and even calls the sculpture "a man with a cucumber nose." A huge nose is associated with an unattractive appearance. The emphasis on this part of the face creates a repulsive effect. In the same ironic over-phrasal unity, the author of the article calls the troll a monster, that is, clearly not a standard of attractiveness. We assume that, in fact, the author of the article 
does not consider this sculpture to be an object of sympathy. The mechanism for creating an ironic effect in this ironic over-phrasal unity is achieved through comparing the object of praise with other images that clearly do not correspond to the idea of the standard and do not evoke sympathy. Thus, in this example, irony is used in order to reduce antipathy towards the object of the story and soften the disapproval of the sculpture's praise.

Example No. 2.

„...the magazine „Intouch“ reports on Lopez's fitness programme:" her recommendation (Tipp) for the beginning of the day, full of energy is to get up at 4 a.m. and dance for 90 minutes. "It is really fun and cheerful, 'says a Latin woman. "Surely this will also make the neighbours really cheerful and joyful."

J. Thomann. Who is Jeanette? // Frankfurter Allgemeine Zeitung (from German) [16].

The author comments on the article about Jennifer Lopez in „Intouch“ magazine. It says that J. Lopez wakes up at four in the morning and dances for an hour and a half. Here the author realises the tactics of praise: the beginning of the day provides her with a cheerful and joyful mood. The author ironically notes that her neighbours obviously will be in the same mood when at four o'clock in the morning J. Lopez turns on the music for dancing. Here is the vocabulary that evokes positive associations: energetic, cheerful, real pleasure. Dancing is associated with high and beautiful art. In itself, it is praiseworthy to get up early and do sports, lead a healthy lifestyle. This behaviour has a positive influence on others, in our case, on the neighbours - it gives them a good cheerful, joyful start of the day.

In this example, the author uses, along with the tactics of praise and refutation of praise, the tactics of reporting the standard. However, they are implicitly presented in the statements, i.e. are based on the background knowledge of the reader, which lies in the fact that at this time of the day it is still dark, the average working day begins much later. Four o'clock in the morning for many people seems to be late at night, but at night it is time to sleep. Thus, the author of the article deliberately creates the following associative picture in the mind of the reader - in deep silence of the night, when innocent neighbours are sleeping peacefully, suddenly cheerful music is heard - J. Lopez begins to dance. Obviously, this picture coincides, rather, with the idea of disturbing the rest at night. Irony in this message, in our opinion, is intended to soften the disagreement with the behaviour of the famous singer.

Example No. 3.

„It's got everything you never want to have, African curls, Venetian carnival masks, Peruvian rugs, tin armour knights, plywood muskets, Tutanchamun made of polyester, horrible copies of "The Last Evening", "Mona Lisa" and eventually there is a table with a built-in wooden globe, under which, simsalabim, is a home bar - all this stuff from all over the world, with which you should obviously feel at home here when you visit Pyeongchang in six years. ... Fortunately, a real Korean island has been made in the artificial lake, as if from calligraphy, with pagodas - pavilions, wooden curved bridges and everything else, so that everyone knows that he has not landed somewhere in Nowhere."

J. Strobel y Serra. How do you ski on the rainbow? // Frankfurter Allgemeine Zeitung (from German) [16].

This article describes the author's impressions after the trip to South Korea, the region where the 2018 Winter Olympics were planned. The author notes that preparations were already in full swing there to receive guests from all over the world during the Olympics. In the shopping and entertainment part of the resort, the organizers tried to present the characteristic cultural items of various countries of the world, from which potential guests and participants of the Olympics were expected. It was implied to create a comfortable atmosphere so that visitors, as the author of the article ironically notes, could make themselves at home. The ironic effect is enhanced by the emphasis on the fact that the created atmosphere is "obviously" similar to the one that is native to foreigners. The irony 
manifests itself here as a contradiction between what truly resembles home and how Koreans see other cultures. The organizers have collected, in their opinion, the most iconic symbols of each country: Venetian carnival masks, Peruvian carpets, etc. But, according to the representatives of these countries themselves, particularly the author of the article, all these things are bad taste and some kind of a junk that no one needs and does not in the least remind of home. This opposition allows to decode the irony in this over-phrasal unity.

The tactics of praise were used in this example at the lexical and syntactical levels. The lexical level of this statement includes expressions with the positive meaning. Thus, the noun "crown" is associated with successful activity, the expression "from all over the world" indicates globality and versatility. The expression "make yourself at home" generally evokes the warmest associations. By themselves, the items listed in the example, indeed, stereotypically correlate with cultural values or historically significant items symbolizing a particular country, for example, knight armour, Tutankhamun, Mona Lisa.

At the syntactical level, we find several homogeneous members in one sentence. The listing of a large number of names is here the indicator of what a great job the Koreans have done. They have collected so many things-symbols of different countries in one place. This characterizes Koreans as a scrupulous and hardworking nation. You will only be in Pyeongchang in six years, and they have already prepared everything.

At the same time, the tactics of refuting the praise are also used. The author unambiguously determines that no one will ever want to have all these things. Listing the items that symbolize the cultural values of different countries, the author uses epithets with a negative connotation. Epithets change the quality of associations evoked by objects of cultural pride and make them negative. The author notes that the muskets are made of plywood, Tutankhamun is made of polyester, and copies of famous paintings are terrible. Such characteristics indicate the low quality and unattractiveness of things and cast doubt on the fact that people with good taste, to which the author of the article counts himself and his reader, keep something similar at home. Consequently, all of the listed items cannot create home atmosphere, they are nothing more than "bad taste and junk".

The tactics of presenting the standard were used in this statement as follows: the author shows a Korean island, as if transferred from calligraphy, with pagoda pavilions and wooden curved bridges. This island makes a great impression on the author with its naturalness, originality, the fact that it represents Korean culture. The author expresses joy that among the artificially created atmosphere of other cultures there is something that allows you to feel belonging to true cultural values and calls for preserving the national identity.

When the use of irony by the author of a newspaper text becomes habitual and regular, we can say that irony is a characteristic feature of the author's speech behaviour and a characteristic of his personal qualities [18]. Referring to the information about the authors provided by the editorial board in the electronic version of the newspaper [16], the preference of journalists of certain genres was confirmed. It was also found out that the selected articles containing ironic statements belonged to a certain list of authors. We counted the number of articles by the authors using irony and presented the result in the percentage of the total number of articles in the sample. The data are presented in Table 1.

Table 2. The use of irony in German journalists' newspaper articles

\begin{tabular}{|l|c|}
\hline \multicolumn{1}{|c|}{$\begin{array}{c}\text { Journalists of } \\
\text { Frankfurter Allgemeine Zeitung }\end{array}$} & $\begin{array}{c}\text { Indicator of the total number } \\
\text { of analyzed articles, } \%\end{array}$ \\
\hline J. Strobel y Serra & 60 \\
\hline J. Thomann & 30 \\
\hline D. Dath & 10 \\
\hline
\end{tabular}


As you can see, $60 \%$ of the selected newspaper articles with irony belong to J. Strobel y Serra, $30 \%$ to J. Thomann, $10 \%$ of the total number to D. Dath. We believe that the frequent use of irony in the texts of the journalist J. Strobel y Serra suggests that such a strategy has become a feature of his speech behaviour.

\section{Conclusions}

In conclusion, let us summarize the results of our study. We made an attempt to investigate irony realized by the authors of newspaper texts as a characteristic feature of their speech behaviour. For this, a number of articles by some German authors who write texts in various newspaper genres were analyzed. It was found that there was no irony in news and analytical newspaper genres, but there was irony in large numbers in the genres of commentary, travel notes and feuilleton, that is, in those genres that allow the authors to present their (personal) evaluation of the described phenomena.

The speech behaviour of journalists was analyzed according to the communicative strategy "the formation of an ironic meaning in the statement". This strategy was presented in the speech by means of certain tactics. As the analysis has shown, journalists used, as a rule, two tactics related to each other: the tactics of praise and, at the same time, the tactics of refuting praise, as well as the tactics of informing the standard, which could be expressed in a statement both explicitly and implicitly, i.e. deduced from the context, communication situation, background knowledge of the communicants. It is in this interaction of tactics that the author forms and the readers understand the ironic meaning of the statement.

The pragmatic effect of journalists' using the strategy "the formation of an ironic meaning in the statement" helps to reduce a negative evaluation of the event or phenomenon.

The analysis also showed that journalists in their activities tended to a certain genre, which allowed us to conclude that their personal characteristics could influence their professional activities.

\section{References}

1. G.G. Matveeva, Diagnosing a linguistic personality and speech behavior of a politician (Rostov n/D, 2009)

2. G.G. Matveeva, Identification of the speaker's social face: theory and practice (Saarbrücken, 2011)

3. T.Yu. Mkrtchyan, Speech Behavior of Journalists in Political Television and Radio Interviews: Based on the Russian and English languages. Dis. ... Cand. philol. Sciences: $10.02 .19,181$ p. (2004)

4. G.G. Matveeva, E.E. Sakharova, Bulletin of the Pyatigorsk State Linguistic University, 1, 88-92 (2012)

5. N.P. Revyakina, E.E. Sakharova, Russian Linguistic Bulletin, 2 (22), 38-40 (2020)

6. E.V. Murugova, The European Proceedings of Social \& Behavioral Sciences EpSBS WUT2018, 416-425 (2018) doi: http://dx.doi.org/10.15405/epsbs.2018.04.02.59

7. N. Boeva-Omelechko, M. Zheltukhina, O. Ryabko, G. Matveeva, E. Murugova, I. Zyubina, Space and Culture, India, 6 (4), 112-121 (2018) doi:

https://doi.org/10.20896/saci.v6i4.387

8. G. Basenko, G. Radchenko, Russian Linguistic Bulletin 3 (23), 34-46 (2020) 
9. T.V. Matveeva, Educational dictionary: Russian language, culture of speech, stylistics, rhetoric (M., 2003)

10. O.S. Issers, Communication strategies and tactics of Russian speech (M., 2017)

11. O. N. Parshina, Russian political speech: Theory and practice (M., 2007)

12. G.N. Leech, Principles of pragmatics (Longman. London and New York, 1983)

13. O. Fomina, O. Potanina, I. Shcherbakova, E3S Web Conf. 210, 16007 (2020) doi: https://doi.org/10.1051/e3sconf/202021016007

14. G.G. Matveeva, Y.P. Khoroshevskaya, VIII International Scientific Conference Transport of Siberia - 2020 / IOP Conf. Series: Materials Science and Engineering 918, 012197 (2020)

15. V. Demchenko, I. Khoroshevskaya, K. Krukov, Communication Barriers of a Construction Company's Network Management Internation Sciencie and Engineering 1079, 032089 (2021) doi: https://iopscience.iop.org./article/10.1088/1757899X/1079/3/032089

16. Frankfurter Allgemeine Zeitung https://www.faz.net/redaktion/?activeInputElement=authorLetter\&author=Name\&quer $\mathrm{yK}=$ Kürzel\&offset $=$ \&authorLetter=A\&showFA=false\&sort=abc\&resultsPerPage $=20$

17. V.A Baskakova, G.G. Matveeva, Pragmalinguistics and practice of speech communication: Proceedings of the V International Scientific and Practical Conference. Rostov-on-Don, 5, 176 (2011)

18. S.G. Agapova, E.S. Milkevich, Scientific notes of the V.I. Vernadsky Crimean Federal University. Philological Sciences, 2 (68), 1, 24-31 (2016) 